\title{
El castellano hablado en un área de contactos
}

\author{
Constantino Contreras Oyarzún* \\ Universidad de La Frontera, Chile
}

\begin{abstract}
Resumen
En este artículo se estudia la variación dialectal del castellano hablado en un área del sur de Chile que presenta: a) carácter lateral con respecto a los centros urbanos y b) contacto con el mapudungun (o mapuche). Los hechos dialectales son observados en textos orales, básicamente narrativos, obtenidos directamente de campesinos adultos, tanto monolingües de castellano como bilingües de castellano y mapudungun. El análisis, que ha abarcado distintos niveles de estructuración lingüística, ha permitido verificar, junto a varios hechos comunes a ambos grupos de hablantes, diferencias en el uso de formas provenientes de la lengua indígena.
\end{abstract}

Palabras clave: dialectología, variación diatópica (o geográfica), lenguas en contacto, influencia mapuche.

*Para correspondencia dirigirse a: Constantino Contreras Oyarzún (insulares@hotmail.com), Departamento de Lenguas, Literatura y Comunicación, Facultad de Educación y Humanidades, Universidad de La Frontera, Avda. Francisco Salazar 01145, Casilla 54 D, Temuco. 


\title{
Oral Spanish in a contact area
}

\begin{abstract}
This is a dialectal variation study of the Spanish language spoken in a Southern area of Chile, a dialectal variety whish is characterized by its: a) colateral geographical nature vis a vis the urban centers; b) constant contact with mapudungun (the language of the mapuche people). The variations are observed in oral texts -essentially narrative ones- taken directly from adult peasants who are either Spanish monolinguals or Spanish-mapudungun bilinguals. Our analysis while including different levels of linguistic structures has facilitated the verifying of some form usages coming from mapudungun, as well a finding similarities and differences between both groups of speakers.
\end{abstract}

Key words: dialectology, geographical variation, languages in contact, mapuche influence on Chilean Spanish.

Recibido: 01/08/09. Aceptado: 02/11/09.

\section{PRESENTACIÓN DEL PROBLEMA}

1.1. En este artículo se pretende esbozar una caracterización del castellano (o español) hablado en un sector costero del sur de Chile, área donde confluyen la Región del Biobío y la Región de la Araucanía.y que reviste especial interés para conocer las particularidades diatópicas de esa variedad, si se consideran dos aspectos fundamentales de su situación geolingüística: a) su carácter de área adyacente a los centros urbanos y b) el contacto del castellano con el mapudungun (o mapuche). Este tema de estudio es parte de un proyecto de investigación de carácter exploratorio llevado adelante en la Universidad de La Frontera ${ }^{1}$. Metodológicamente, la investigación se

${ }^{1}$ El proyecto se titula "Contactos hispano-mapuches en el área costera de la VIII y IX Regiones (Estudio lingüístico-etnográfico)" y se ha llevado adelante con el patrocinio de la Dirección de Investigación y Desarrollo de la Universidad de La Frontera (Temuco, Chile). El grupo de trabajo está integrado por: Mario Bernales (investigador responsable), Luis de la Barra y Constantino Contreras (co-investigadores). Aspectos generales del presente trabajo 
inscribe en la microdialectología, puesto que abarca un territorio relativamente pequeño, pero ha utilizado la misma técnica de la macrodialectología: aplicación de un cuestionario que comprende básicamente ítemes del léxico (Zamora 1988a: 258). El registro y estudio de textos orales es algo adicional, pero necesario en cuanto ofrece muestras no solo de léxico, sino también de otros niveles de estructuración lingüística: fónico, morfosintáctico y articulación textual (o discursiva). Los materiales para el presente estudio - de carácter cualitativo (Aguirre Baztán 1997)- provienen de los textos orales registrados durante 2007 y 2008 en distintas localidades del área geográfica señalada y emitidos por campesinos de escasa instrucción escolar, cuyas edades van desde 50 hasta 80 años. En atención a la realidad etnolingüística de esta área (culturas y lenguas en contacto) (vid. Zimmermann 1995; Elizaincín 2007), se han registrado muestras tanto de monolingües de castellano como de bilingües de castellano y mapudungun. En esta materia, la dialectología entra necesariamente en relación con aspectos que suelen incumbir a la sociolingüística (cfr. Moreno Fernández 1990; Contreras 2005).

1.2. En el área geográfica del presente estudio, de límites cercanos al antiguo territorio lafkenche (o sea, de la gente que vive cerca del mar), el mapudungun es hablado preferentemente por mapuches de mayor edad y ha perdido vitalidad entre los jóvenes, pero todo el que habla dicha lengua indígena ha debido aprender como segunda lengua el castellano, para tener que entenderse con la sociedad dominante. En cambio, la sociedad no mapuche, fundamentalmente de ascendencia hispano-criolla, habla únicamente castellano. En todo caso, las influencias culturales y lingüísticas han de ser recíprocas, aunque este estudio limita su objeto a hechos dialectales del castellano hablado en un espacio reducido, donde es de esperar que algunos de tales hechos sean explicados por influencia del mapudungun, dados los contactos sociales de los hispanohablantes con los indígenas, más intensos desde fines del siglo XIX, cuando el proceso militar llamado "pacificación de la Araucanía" vino a facilitar el asentamiento de colonos al sur del río Biobío (cfr. Cerda Hegerl 1996). Hay que hacer notar también que el bilingüismo observado en la población mapuche es de carácter diglósico (cfr. Zamora 1988b: 268; Fishman 1988: 120), ya que normalmente su lengua primaria ha quedado limitada a los ámbitos familiar, amical y ceremonial, en tanto que la segunda lengua es empleada para relacionarse

fueron expuestos en calidad de ponencia en el XV Congreso de la ALFAL (Asociación de Lingüística y Filología de la América Latina), celebrado en Montevideo (Uruguay) en agosto de 2008. 
con el resto de la sociedad chilena. Postulamos que el castellano hablado por los mapuches bilingües presentará algunos rasgos diferentes del hablado por la población de ascendencia hispano-criolla, dado que en los indígenas el contacto interlingüístico ha sido más directo.

\section{HECHOS DEL NIVEL FÓNICO}

2.1. Las tendencias fónicas que se observan en los materiales grabados coinciden con las observadas en otras partes de la Araucanía (Contreras 2005) y con las más regulares del castellano (o español) popular del resto del país (Oroz 1966): seseo y yeísmo generalizados; aspiración del fonema sibilante en situación implosiva: $-s>-h$, que cuando llega a la elisión trae dificultades para la distinción del plural frente al singular; debilitamiento o elisión de $-d$ - intervocálica en las terminaciones $-a d o>-a(d) o$, -ido $>$ $-i(d) o$; y también en situación final de palabra, como en ciuda(d) o salu(d); lateralización de la consonante vibrante simple ante lateral (-rl- > -l.l-); y reducción silábica de algunas palabras por apócope, como en para $>$ pa( $\mathrm{ra})$ y pues $>$ pu(es), o por la extendida tendencia antihiática, como en pasear $>$ pasiar o pelear > peliar, y que L. Sáez llama "diptongación de hiatos" (1999: 25).

2.2. No aparece nada en el habla de los informantes que pudiera favorecer la tesis de Lenz, rebatida en su tiempo por Amado Alonso, acerca de la influencia del fonema araucano alveolar (o prepalatal) retroflejo africado áfono /tr'/ en la articulación asibilada del grupo consonántico [tr] en hispanohablantes (cfr. Alonso 1961: 268-321). Lo que sí se observa es que mientras un monolingüe de castellano ha adoptado y adaptado como préstamos las voces tiuque, traro y treile, nombres de conocidas aves regionales, el bilingüe de castellano y mapudungun las pronuncia según el sistema fónico vernáculo: $t r$ 'iwke, $t r$ 'aru, $t r$ 'egül. Igualmente, mientras los monolingües de castellano cuando utilizan palabras mapuches que tienen el fonema nasal velar /ng/ y/o la sexta vocal /ü/ (fonema alto posterior no redondeado) (cfr. Salas 1984; Hernández, Ramos y Huenchulaf 2006), recurren a fonemas del castellano, los bilingües de castellano y mapudungun son fieles a la lengua indígena. Así, mayor fidelidad a las formas indígenas presentan quienes pronuncian Ngünechen (el ser supremo) y ngillatun 
(ceremonia ritual o rogativa) que los que pronuncian simplemente Guenechén y guillatún.

2.3. Otro hecho - más esporádico- es el debilitamiento del fonema bilabial sonoro /b/, que a veces llega a la elisión (como en buscar > uscar, estaba $>$ esta'a, también > tam'ién) o en contacto con vibrante o lateral puede llegar a la vocalización (cabro > cauro; habla $>$ haula). Tales realizaciones se observan preferentemente en los informantes bilingües de castellano y mapudungun y este hecho sí puede atribuirse a la influencia de la lengua vernácula, pues es sabido que ella no posee un fonema /b/, como el del castellano.

\section{EL LÉXICO: TRADICIÓN HISPANO-CRIOLLA E INDIGENISMO}

3.1. La lateralidad del área de estudio significa poco contacto con los centros poblados, siempre más propensos a la innovación y al proceso de globalización. Ello ayuda a explicar el carácter conservador del léxico. Aparte de la base léxica panhispánica, cabe distinguir en los textos orales analizados al menos tres grupos de voces de interés dialectológico: 1) unas cuantas palabras que parecen supervivencias de otros tiempos enfrentadas a formas más recientes; 2) un grupo de voces muy propias de la "cultura huasa"; 3) voces procedentes de la lengua mapuche.

3.2. Del primer grupo se pueden mencionar varias voces del fondo idiomático castellano, más algunos préstamos incorporados en distintos momentos de su historia, pero cuyo uso se ve actualmente restringido, frente a otras voces más vitales: pollera 'falda', enagua(s) 'combinación' (como prenda interior femenina), paltó (por paletó) 'chaqueta, americana', escarpines 'calzado antiguo de una sola pieza', halda(d)a 'lo que cabe en el halda o arpillera que sirve de envoltorio', almud 'medida de capacidad para áridos equivalente a unos ocho litros', fanega 'medida de capacidad para áridos equivalente a unos siete y medio almudes'; maquila 'porción de trigo o harina que corresponde al molinero por la molienda' y también 'lo que se debe pagar por el uso de una maquinaria agrícola'; burujo y brujo, por borujo, variante antigua de orujo 'hollejo de la uva' (y, por extensión, de la manzana), sarazo 
'maíz tierno', sobera (d)o 'desván, entretecho', sierpe 'culebra de gran tamaño', jumento 'asno', vihuela 'antiguo instrumento de cuerda', sanjuriana, variante de sajuriana 'antiguo baile de a dos, con zapateo y escobillado', cochezuela, por choquezuela 'rótula', celebro 'cerebro' y variantes fónicas de formas verbales, como: dentrar, vaiga y haiga. Recordemos que algunas variantes consideradas actualmente propias del habla rústica, como celebro, dentrar y haiga, fueron utilizadas con toda naturalidad por autores del Siglo de Oro español (cfr. Lapesa 1981: 367-417).

3.3. El segundo conjunto de voces proviene seguramente de campesinos de habla hispana desplazados desde la zona centro-sur del país. En efecto, primero la presencia de españoles y después la de criollos nunca fue más que esporádica al sur del Biobío hasta fines del siglo XIX. Solo a partir de entonces, una vez morigerada la resistencia indígena, los hispano-criollos pudieron traspasar la "frontera natural" que separaba ambas poblaciones y que era precisamente el río Biobío, y de esa manera pudieron asentarse en los territorios situados al sur de dicha frontera (cfr. Cerda Hegerl 1996). El campesino típico de la zona central del país es el huaso o guaso. Su campo de trabajo es el agropecuario. El origen de la denominación está probablemente en la voz quechua huasu (según Morínigo 1966: 296). Huaso es voz más arraigada en el centro del país y desde allí se ha desplazado hacia el sur. En los textos orales aparecen mencionadas también la forma femenina huasa y su diminutiva huasita, que hacen referencia a la esposa o a la novia del huaso. Otra voz campesina relativa al mundo del huaso es la denominación china. Esta voz sí procede del quechua, donde significa 'mujer' o 'hembra' (Morínigo 1966: 191). En el castellano de Chile ha pasado a significar 'empleada doméstica', acepción que ya está en desuso, según el DHACH (1978: 91). En los textos orales revisados, la voz china alude principalmente a la 'enamorada del huaso'.

3.4. Para denominar la indumentaria de este hombre típico hay varias palabras panhispánicas, pero hay otras que son particulares. Por ejemplo: la voz chamanto, formada seguramente de un cruce entre la voz mapuche chamal ('manta de mujer' y también 'tejido que usaban los varones cruzado entre las piernas y atado a la cintura') y la castellana manto, - $a$. (cfr. Morínigo 1966: 172). El chamanto del huaso es manto de lana fina, a menudo con listas de colores, para lucirlo en días de fiesta, a diferencia del poncho, que es más rústico. De origen quechua es la voz chupalla, referida al 'sombrero de paja de alas anchas' y procedente de achupalla, nombre 
de una planta de las agaves (Buesa Oliver 1965: 65). La estampa del huaso se complementa con la de su cabalgadura, para la cual suele utilizar varios nombres amistosos que ponen de relieve algún detalle físico, como manco, manquita, overo, tordillo; o alguna habilidad, como campero, corralero o topia(d)or. Con referencia al caballo, hay una palabra particularmente interesante por su metonimia. Según el DRAE, el término prevención significa, entre otras acepciones, 'provisión de mantenimiento o de otra cosa que sirve para un fin' (2001/2: 1830). En el habla del huaso la forma plural prevenciones significa 'alforjas que llevan los jinetes en los caballos' (cfr. DHACH 1978: 187). Otros aspectos: La cabalgadura es estimulada con una especie de 'látigo' o "rebenque" llamado guasca, cuyo nombre proviene del quechua wáskha 'soga, lazo, cuerda' (Buesa Oliver 1965: 56). Si el caballo se vuelve demasiado remolón, el campesino se ve en la necesidad de darle una chanca, es decir, una 'tunda o paliza'. La voz chanca proviene del quechua chankay 'moler, triturar' (Morínigo 1966: 174) y era usada primariamente con referencia a la trituración de piedras, minerales o granos (DHACH 1978: 86). De ahí proviene la expresión chancacazo, que significa 'golpe fuerte' (Oroz 1966: 286). También aparece usada la voz arción, que se refiere a la 'correa que une el casco de la silla de montar con el estribo' (cfr. DHACH 1978: 54) y que es una clara variante de la voz hispana de origen árabe ación (vid. DRAE 2001/1: 30).

3.5. En distintos momentos de contactos de los campesinos de habla hispana con los indígenas del norte de Chile y con los indígenas del sur del Perú, de lengua quechua, debieron ingresar las mencionadas voces de ese origen que aquí se han señalado. Y hay varias más, relativas a determinados aspectos de los trabajos agropecuarios. Ejs.: echona, nombre de la 'hoz', y seguramente tomada del quechua ychuna (Morínigo 1966: 227); callana 'tiesto para tostar cereales' ( $<$ de callana 'olla chata', Morínigo 1966: 117), charqui 'carne seca al sol o al aire' (cfr. Morínigo 1966: 179), mote 'trigo sin cascarilla y cocido' ( $<$ de mut'i 'maíz hervido', Buesa Oliver 1965: 57), poroto 'alubia, fréjol o judía' (< purútu, Buesa Oliver 1965: 63), zapallo 'calabaza' (< sapallu, Morínigo 1966: 687), chacra 'propiedad rural de reducida extensión destinada a diversos cultivos' (< chac-ra 'huerta, sementera', Morínigo 1966: 168), de donde se ha derivado chacarero 'agricultor horticultor', mingaco 'trabajo cooperativo entre vecinos, que suele culminar festivamente' (< minkay 'ayudar en el trabajo', Morínigo 1966: 216), etc. 
3.6. Las voces mapuches que aparecen en los textos orales se pueden agrupar en tres subconjuntos. El primero comprende voces simbólicas de la cultura vernácula que los mapuches incorporan en su discurso en castellano como elementos de resistencia e identidad. Por ejemplo: la palabra Ngünechen, nombre del 'ser supremo y todopoderoso', llamado también Chaw Ngünechen o Chaw Dios (por influencia del Dios Padre cristiano). Algunos mapuches mencionan la dualidad Chaw Dios / Ñuke Dios (o sea, Padre Dios / Madre Dios), modo particular de concebir la idea de la divinidad. Otra palabra clave de la cosmovisión mapuche es Ngillatun, que es el nombre del principal ceremonial religioso de esa etnia, destinado a dar gracias a Chaw Dios por los beneficios concedidos y a rogar para que siga entregando salud, sol y lluvia para los sembrados, alimentos y mejor convivencia. El ceremonial incluye ofrendas de alimentos y otros ritos de fertilidad y también reunión de las familias para compartir la comida, plegarias, música y danza. Además, sirve para recordar a los antepasados y fortalecer la identidad del pueblo mapuche. Otras palabras clave: ngillatuwe 'suelo demarcado en forma circular para los ritos del Ngillatun', machi 'curandera', pero también 'médium entre Chaw Dios y las personas en los ritos del Ngillatun'; kuriche 'joven que ayuda a la machi en sus rituales', machitun 'ritual de la machi para sanar a un enfermo', kultrung 'tambor ceremonial', rewe 'tronco de árbol (principalmente de canelo) con escalones para que se suba la machi en sus ritos de sanación', Wetripantü 'año nuevo mapuche', que coincide con el inicio del invierno y se celebra la noche del 23 al 24 de junio, longko 'dirigente o líder de una comunidad mapuche', werken 'emisario o mensajero de un longko a otra autoridad', ruka 'vivienda con paredes y techo de paja'. También aparecen mencionadas las voces trutruka y pivilka o pifülka, relativas a dos instrumentos de viento muy propios de la cultura mapuche, palin 'juego de pelota en el que cada jugador utiliza un palo curvo para impulsarla' (chueca para los hispanohablantes), wampu 'canoa destinada a navegar a remo por ríos y lagos' (y también 'ataúd'), metawe 'cantarito de greda', muday 'bebida de maíz u otro cereal fermentado', pentukun 'saludo y conversación ceremoniosa', ngütr'am 'relato realista', epew 'relato de ficción', $u ̈ l$ 'composición poético-musical'. En el campo de las creencias en seres dotados de poderes sobrenaturales para producir maleficios, se menciona el wekufü 'espíritu maligno que puede ocasionar graves enfermedades', el kalku 'brujo o hechicero', el chongchong o chonchon 'ave aliada de un brujo' o bien 'la cabeza del brujo que se desprende del cuerpo y vuela para salir a hacer el mal por las noches', witr'analwe o wichanalwe 'espíritu de un muerto buscado como aliado por un brujo para hacer el mal' y anchimalen 'espíritu que aparece por los caminos en forma de enano'. El P. Augusta da la variante anchimallen ([1916]1991: 80) y Salas, la forma añchimalleñ (1992: 228). 
3.7. Otras voces mapuches indican relaciones de tipo social: la oposición wentru / domo equivale a 'hombre' vs. 'mujer'; de la oposición peñi / lamngen, la primera es usada por el varón para saludar o referirse a un 'hermano' y, por extensión, a cualquier varón que merezca un trato cordial; la segunda es usada por la mujer para saludar o para referirse tanto a un 'hermano' como a una 'hermana' o a cualquier persona que merezca un trato cordial (cfr. Augusta [1916] 1991: 170 y 110); la oposición mapuche/wingka señala la distinción étnica entre la 'gente de la tierra' y el 'advenedizo'. Cualquier 'individuo no mapuche' es considerado un wingka, especialmente el de ascendencia hispana. En un artículo anterior postulábamos que la denominación wingka nacería seguramente en los tiempos precolombinos de la invasión inca, cuya presencia se extendió hasta el río Maule (Contreras 2005: 201). La oposición mapuche / chileno marca la diferencia entre el hombre de la etnia indígena que, por su historia, lengua y tradición cultural no se siente plenamente integrado al Estado nacional y el que sí está integrado, por historia, lengua y tradición cultural diferentes.

3.8. En un tercer subgrupo están las voces mapuches más generalizadas y que funcionan como préstamos de la lengua vernácula al castellano de esta área y seguramente también de otras regiones del país. Chuico o chuica $(<$ chuyccu 'tinajita', Morínigo 1966: 202) es palabra bastante conocida con la acepción de 'damajuana cilíndrica generalmente de vidrio que sirve de envase para el vino' y aquí conserva la acepción más antigua de 'cántaro o tinaja de greda'. La voz mapuche rokin, relativa a las 'provisiones para un viaje', parece tener un uso solo local o tal vez regional. Suele alternar con cocavi $(<$ del quechua ccoccavi 'provisión de víveres para un viaje', Morínigo 1966: 140). Algunas voces de filiación mapuche son nombres de especies de la flora regional: nalca $(<$ nalka) 'pecíolo de la planta llamad $a$ pangue', quillay ( $<$ kullay), boldo $(<$ fol.o), quila $(<$ kula 'especie de caña' o 'bambú chileno'); las varas de esta planta son los colihues (< koliu 'caña' y we 'colectivo o plural'), boqui 'especie de liana' (voqui $<$ foki), collochos ( $<$ cast. cogollos). Otros términos designan moluscos: macha 'molusco bivalvo muy apetecido', dollim o dóllimo $(<$ dollüm 'mejillón pequeño de ríos o lagunas'), chape 'lapa' y loco $(<$ loko $)$. De filiación mapuche son, además, varios nombres de aves cantoras, muy comunes no solo en el área de estudio, sino en varias regiones del país: chincol $(<$ chinkol), tenca $(<$ tr'enka), diuca, $(<$ diwka); chercán $(<$ chedkañ); pero también los hay de aves conocidas por otras características: lloica (< lloyka 'petirrojo'), caiquén (< kankwen 'ganso silvestre'), peuco (< pewku 'gavilán'), tiuque (< tr'iwke), treile $(<$ tr'egül), traro $(<$ tr'aru), pequén $(<$ pekeñ). A veces se 
alude también al wilki, nombre mapuche que alterna con el hispánico zorzal y ocasionalmente también se menciona el chuncho o chucho, que es una variedad de 'búho'. Todos estos nombres mapuches relativos a especies de la flora y la fauna son muy vitales en la oralidad y, además, constan en obras lexicográficas junto a los equivalentes nombres científicos (vid. Augusta [1916] 1991, Grau 1998; Hoffmann y Lazo 2000).

\section{ALGUNOS HECHOS DEL NIVEL MORFOSINTÁCTICO}

4.1. En gramática se entiende por concordancia "la coincidencia obligatoria de morfemas entre varias unidades distintas que forman otra superior, como entre sustantivo y adjetivo para formar un sintagma nominal o entre núcleo de sujeto y núcleo de sintagma verbal para formar una cláusula" (Hernández Alonso 1995: 126). Si los componentes estructurales del sintagma nominal son / + - Det + Nu + - Ay / (determinante, núcleo, adjetivo adyacente), los elementos de la infraestructura morfemática de género y número han de funcionar en las relaciones de estos componentes. Ahora bien, si por alguna razón, la concordancia no se cumple, surge un hecho de discordancia, tal como se suele producir en los textos generados por mapuches que tienen el castellano como segunda lengua.

Ejs:

(1) Entonces tengo mucho cosa que contar (JRPC/B1/b) ${ }^{2}$.

(2) ... para que no llegara el fuego a(d)onde estaba la madera acastilla(d)o (JRPC/B1/b).

(3) ... porque ése dicen que tam(b)ién lo manija una persona malo (PHA/A6/b).

(4) Hay idea claro $(\mathrm{PHA} / \mathrm{A} 6 / \mathrm{b})$.

En los ejemplos citados hay discordancia de género. La discordancia de número suele producirse también, en especial cuando el debilitamiento

${ }^{2}$ En cada ejemplo citado se indicarán:

- Las iniciales del nombre del informante

- Región: $\mathrm{A}=$ Araucanía + número del sector/ o $\mathrm{B}=$ Biobío + número del sector

- Calidad del informante: $\mathrm{m}=$ monolingüe $/ \mathrm{o} b=$ bilingüe. 
de $-s$ llega a percibirse como elisión, lo que sucede a lo menos en uno de los componentes relacionados: los buenos amigo(s), los materiales caro(s), las malas junta(s). Pero este hecho se observa también en los textos de los informantes monolingües de castellano.

4.2. Algunas discordancias de género y número alcanzan a veces a las oraciones atributivas (o sea, las de predicado nominal), donde el sujeto debiera concordar con el atributo (sustantivo, adjetivo, pronombre, etc.), "que semánticamente es el elemento relevante del predicado" (Gómez Torrego 2002: 40). Naturalmente, una oración atributiva puede ser independiente o estar subordinada a otra principal.

Ejs.:

(5) No estaba escaso la leña (IPC/A5/b).

(6) El mapuche dicen que son tonto(s) (JRPC/B1/b).

(7) Hay machis que son buena(s) y hay machis que son sucio (JPMQ/ A6/b).

Estas discordancias han de ser explicadas por la dificultad que representa la distinción genérica para el bilingüe de mapudungun y castellano, pues para él, en el sistema de su primera lengua, no hay marcas morfemáticas específicas que permitan la distinción de género en las categorías nominales; tampoco las hay para distinguir el número. En el mapudungun, cuando hay necesidad de expresar la idea de género se recurre a distinciones léxicas (wentru 'hombre, macho' / domo 'mujer, hembra') o a elementos contextuales (Salas 1992: 93 -94); y para expresar la idea de pluralidad se recurre normalmente a la partícula externa $\mathrm{pu}$.

4.3. Otra clase de concordancia es la que relaciona el sujeto (S) con el verbo (V). "La concordancia en "número" y "persona" -dice Hernández Alonso- es lazo indisoluble y privativo de la relación sujeto-verbo" (1995: 71). En los textos observados las discordancias que se producen en este nivel son muy esporádicas. El verbo en mapudungun tiene una estructura muy particular, que incluye formas no finitas y formas finitas o personales, con una flexión caracterizada por marcas muy claras de modo, persona y número (singular, dual y plural) (vid. Salas 1992). Frente a ello, se podría esperar que los mapuches que tienen como segunda lengua el castellano tuvieran mayores dificultades con el paradigma verbal de esta lengua; sin embargo, al menos en el área de estudio, se nota que su nivel de competencia 
es bastante eficiente, aun cuando su repertorio verbal no es muy amplio. Las discordancias en este plano son únicamente ocasionales, como en los siguientes ejemplos:

(8) Esas cosas importante(s) me quedó grabado a mí a esa eda(d) de más o menos de ocho a nueve años (JRPC/B1/b).

(9) ... nos hizo clases los padrecitos, unos abogados, unos peñicitos $(\mathrm{JRPC} / \mathrm{B} 1 / \mathrm{b})$.

4.4. Mayores dificultades revela el uso preposicional. Como el mapudungun tiene solamente dos preposiciones - meo, que tiene valor locativo, direccional, instrumental, causal o temporal, según el contexto, y püle, que indica la dirección general de un movimiento de traslado (Salas 1992; 103105)-, es explicable que el hablante mapuche al enfrentarse a un sistema preposicional más complejo, como es el del castellano, manifieste inseguridad. El hecho puede alcanzar solo muy ocasionalmente al habla de los monolingües de castellano.

La preposición $a$ suele estar ausente como elemento introductor de un complemento directo personal (CD):

(10) Cuidaba () las señoras que estaban con guagua (JPMQ/A6/b).

(11) Claro, () usted mi papá no lo conoce (PP/A4/b).

(12) - Señorita, ¿no encontró $\mathrm{p}$ (or) allá () una gringa que iba a medio besar? (JAVQ/A6/m).

(13) Y () la hija la tenían presa (IPC/A5/b).

También esta preposición puede faltar como elemento introductor de complemento indirecto $(\mathrm{CI})$ :

(14) Y eso () nosotros no nos gusta (MINH/B1/b).

(15) No, () ese hombre no le roba nadie (JPMQ/A6/b).

(16) ...entonces () el otro le tocó menos (MBCV/B1/m).

4.5. Presencia o ausencia de la preposición $a$ en perífrasis verbales se puede encontrar en los textos de un mismo hablante:

(17) Este domingo yo voy a llamar a mi gente (JRPC/B1/b).

(18) Fuimos tam(b)ién () enfrentar los problema(s) (JRPC/B1/b). 
En el complemento del nombre con construcción preposicional (vid. Gómez Torrego 2002: 26), el mapuche que habla castellano presenta también realizaciones en que la preposición, en estos casos de, está ausente, de modo que resulta una estructura de dos nombres en aposición, como en los siguientes ejemplos:

(19) ... mi madrina me volvió a tomar de kuriche, servidor () machi en el curar (JRPC/B1/b).

(20) Entonces hay un bajo muy bonito, que está antes de llegar al puente () tierra $(\mathrm{PP} / \mathrm{A} 4 / \mathrm{b})$

(21) Antiguamente había olla () greda (IPC/A5/b).

(22) Como no había sal, usaban agua () mar no más pu(es) (IPC/A5/b).

En la estructura resultante, el primer elemento es el determinado y el segundo el determinante, como en servidor machi, puente tierra, olla greda, agua mar. El castellano tradicional no desconoce el procedimiento de formar palabras mediante sustantivos que han quedado en aposición por haberse omitido la preposición de, como en casatienda, bocajarro o bocamina. Pero que los ejemplos encontrados en los textos orales correspondan solo a bilingües de castellano y mapudungun nos lleva a pensar que el empleo de la estructura de dos nombres en aposición en el castellano de estos hablantes estaría reforzado por la análoga estructura del mapudungun, aunque en dicha lengua no siempre el elemento determinado está en primer lugar, como se puede advertir en los dos últimos de los siguientes ejemplos de la toponimia: Rayenko (< rayen 'flor' + ko 'agua' = 'flores del agua'); Malalkawello $(<$ malal 'corral' + kawellu 'caballo' = 'corral de caballos'); Lamewapi $(<$ lame 'lobo' + wapi 'isla' = 'isla de lobos'); Lilecura $(<$ lile 'pato lile' + kura 'piedra') = 'piedra de los patos llamados lile') (vid. Bernales 2002).

4.6. En un estudio anterior sobre el castellano hablado por mapuches en una comuna muy superior en densidad de población indígena (Contreras 1999), se observaba alternancia entre la presencia y la omisión (o ausencia) de artículo. Y se atribuía esta omisión (o ausencia) a la influencia del mapudungun, puesto que esa lengua tradicionalmente ha carecido de artículo, aunque en tiempos recientes, y tal vez por influencia del castellano, han venido a asumir esa función el demostrativo chi (definido) y el numeral kiñe (indefinido) (Salas 1992: 40 y 95). En los textos orales registrados en el área del presente estudio, la ausencia de artículo es un hecho muy esporádico. 
Ejs.:

(23) ... si puedo venir parcha(d)o ando parcha(d)o, para que digan que ( ) mapuche es laurauor de la tierra (JRPC/B1/b).

(24) Trabajamos a ( ) buena de Dios nu más (JPMQ/A6/b).

(25) Todo eso conversábamos ( ) mapuche antes (PHA/A6/b).

(26) Si hay visícula, ( ) doctor lo saca (PHA/A6/b).

4.7. La estructura dialogada en que se desarrolla el discurso de los personajes, como forma enmarcada en una narración, trasunta otros rasgos del habla cotidiana. Uno de esos rasgos es el voseo, pero, por lo general, no el "voseo pronominal" (uso de vos), hecho considerado como supervivencia degradada de un uso que en otros tiempos gozó de mucho prestigio (cfr. Zamora Vicente 1979: 400-410; Moreno de Alba 1991: 167-175), sino del "voseo verbal" (formas de segunda persona de plural para la segunda de singular). Estas formas verbales, cuando son del presente de indicativo, se ajustan a las siguientes terminaciones -ái(s) (para verbos en -ar), -is (< -éis) (para verbos en -er), -ís (para verbos en -ir), además de la forma sois (del verbo ser), y aparecen solas o combinadas con el pronombre tú o con la forma átona te. De modo similar, aparecen las terminaciones -ás e -ís para formas con función imperativa, en ausencia de las canónicas. A veces el habla de un mismo individuo oscila entre el uso de una forma verbal voseante y otra no voseante. En general, el voseo verbal (de tipo mixto, esto es, combinado con formas de tuteo) es un uso inconstante y cuando ocurre es para dirigirse a un interlocutor igual o inferior en su rol social. En cambio, para dirigirse a un superior aparecen otras formas de tratamiento, principalmente el pronombre usted (o ustedes) concertado con una forma verbal de tercera persona, según la norma común.

Ejs.:

(27) - ¿Y qué es eso que tienes ahí?

- Esto es a(d)onde fumo yo pu(es).

- ¿Ah, fumái(s) en eso?

- Sí pu(es).

- ¿Y me podís convidar a mí? (JBVS/B3/m).

(28) Ya. Después el hermano mayor le pidió que fuera a moler el trigo:

- Mira -le dijo-, antes de llegar al molino tenís que aventar el trigo, $\mathrm{a}(\mathrm{d})$ onde haiga una partecita más alta, una loma -le dijo--, porque vivían en un bajo, así, (d)onde no llegaba viento. Entonces -le dijo- llevás esta carpa y en la loma aventás el trigo. Lo levantás así -le dijo- $p a(r a)$ arriba $p a(r a)$ que vuele toda la paja -le dijo-y no salga la harina con paja. Y de un saco de trigo -le dijo- tenís que pagar un almud allá, al molinero (DC/B2/m). 
4.8. En estos textos orales se perfila, además, una tendencia más general del castellano hablado y que aquí aparece sobre todo en las muestras dadas por wingkas. Se trata del uso de un clítico anticipador de un complemento indirecto (CI), y a veces también de un complemento directo (CD), que parece "redundante" o "pleonástico", según Kany (1969: 139 y 148), y que se manifiesta en particular cuando el complemento está constituido por "un pronombre o un nombre personal enfático". El citado autor sostiene que este uso gana cada vez más terreno especialmente en el habla coloquial hispanoamericana (y en algunos textos literarios). La reiteración de un complemento obedece, sin duda, a la necesidad de hacer inequívoca la referencia.

Ejs. :

(29) Entonces los hermanos le tomaron envidia al menor $(\mathrm{MOAB} / \mathrm{B} 2 / \mathrm{m})$<smiles>[SiH3]Cl</smiles>

(30) $\quad \ldots y$ le(s) llevaba comi(d)a a los presos (DNB/B2/m).

$\mathrm{CI}$-.----CI

(31) No lo pillaron nunca ese entierro (JACP//B3/m).

$\mathrm{CD}$-.--CD

(32) Yo no los conozco los corderos (MBCV/B1/m).

$\mathrm{CD}$--- $\mathrm{CD}$

(33) Los crió los perros él; y los perros le daban el sostén a él

$\mathrm{CD}$-- CI --- CD

(SRCS/B2/m).

4.9. Otro hecho de la variación morfosintáctica es el ocasional uso del pronombre átono los (de tercera persona de plural para complemento directo) como sustituto de nos (de tercera persona para complemento directo o indirecto). El uso de los en vez de nos en su parte superficial puede captarse como una simple confusión por similitud fónica, pero dichas formas contienen diferencias más profundas de significado y función. Por eso, este uso puede provocar equívocos en la comunicación, aunque casi siempre el contexto suministra la información necesaria para evitar que ello ocurra. Es necesario recalcar que este rasgo dialectal aparece solo esporádicamente en los materiales registrados, a pesar de haber sido señalado como altamente arraigado en el habla popular chilena (Oroz 1966: 297).

Ejs.:

(34) Los vamos a ir de este lugar (DNB/B2/m).

(35) Así que se apagó la luz y los vinimos (JACP/B3/m). 
(37) Así dicía mi papá, lo(s) contaba a nosotro(s) (IPC/A5/b).

\section{ALGUNOS ASPECTOS DE LA COHESIÓN TEXTUAL (O DISCURSIVA)}

5.1. El sentido global de un texto, o sea, su coherencia, depende en gran medida de cómo están articuladas las distintas partes que lo componen. Lo que muchos autores llaman la cohesión textual es precisamente esa "trabazón entre los constituyentes del texto" o "conjunto de todas aquellas funciones lingüísticas que indican relaciones entre los elementos de un texto" (Casado Velarde 1995: 17-18). Pero la coherencia va más allá de dichas relaciones internas, pues se apoya también en elementos extralingüísticos. Es muy importante tener en cuenta este plano pragmático, sobre todo en el caso de la oralidad, porque ésta funciona precisamente en situaciones concretas de comunicación. En este panorama incluimos algunas observaciones sobre estos aspectos, ya que pueden tener algún interés para la dialectología.

5.2. Los textos contienen algunos marcadores de la relación comunicativa entre el sujeto de la enunciación y el destinatario (individual o colectivo, según el caso). Así, por ejemplo, y de modo muy obvio, aparecen elementos autorreferenciales (pronombres personales, formas verbales en primera persona) cuando el hablante ha participado en los hechos referidos. Esto ocurre en textos sobre experiencias personales, narradas tanto de modo formal como en sentido anecdótico. Pero más novedosa es la autorreferencia cuando el hablante se involucra en los sucesos de un relato de ficción, como en el siguiente ejemplo, donde el narrador persigue claramente un efecto humorístico:

(38) Un día fue un tontito, como yo, y le dijo a su mamá que él quería ir [a presentarse al concurso real] (DC/B2/m).

Casos como éste son excepcionales. En cambio, son más regulares algunas formas de apelación al destinatario para que éste mantenga la atención frente al mensaje que se le está entregando. Las formas más comunes son: oiga, ¿ve?, ¿ven?, ¿sabe qué?, usted sabe, caballeros, fijate (usada 
preferentemente por mapuches). En verdad, solo algunas de estas formas cumplen la función de apelar al destinatario; otras cumplen una función meramente fática, es decir, de apoyo a la continuidad de la comunicación.

Ejs.:

(39) (Es)taba bueno el mar pu(es), oiga, mansito el mar. Y entonce(s) se podía ir a(d)onde había una piedra grande a(d)entro $(\mathrm{OELlH} / \mathrm{A} 4 / \mathrm{b})$.

(40) - Bien, y a lo que uste(d) vuelva, yo le voy a pagar: to(d)o lo que hace mi bastón.

Miren cómo eran antes $p u(e s)$. ¿Ven? (VMM/A6/m).

(41) ... Y el doctor, uste(d) sabe que el doctor es así pu(es). Ve una gente pobre, se está muriendo el pobre y no le hace nada $p u(e s)$ (JPMQ/ A6/b).

(42) ¿Y sabe qué?: eso, yo pensé, sería también ánima no más o alguien que estaba ahí y yo lo miraba $p u(e s)$. Pero que... ¿sabe qué?: una señora a mí me lo contó igualito a como lo vi yo (JACP/B3/m).

5.3. En la articulación interna de los textos, y particularmente de los textos narrativos, es notoria la distinción que se hace entre el discurso del narrador y el de los personajes. A diferencia de lo que sucede en las narraciones escritas, propiamente literarias, las narraciones orales resultan muy limitadas en el uso de los "verba dicendi" (verbos que introducen el habla de los personajes). Entre las escasas formas que aparecen utilizadas en las muestras cabe señalar: preguntó, contestó, gritaba, decía, dijeron y dijo. En las narraciones orales, sobre todo la reiteración de dijo (y eventualmente de otras formas del verbo decir) es una constante que encuentra justificación solo en la necesidad del narrador de diferenciar el habla de los personajes con respecto a su propio hablar. Por lo general, un clítico antepuesto sirve para señalar al destinatario del mensaje.

Ejs.:

(43) Entonces él le dijo:

- No se le dé na(d)a. Yo tengo una virtu(d) -le dijo-. Si acaso uste(d) se viene conmigo, yo le salvo la vida.

- ¿Qué me va a salvar? -si que $\underline{\text { dijo-}}-$, si es un gran animal. Ése se traga enterita a una persona (JMP/B3/m).

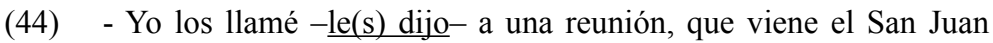
-le(s) dijo- $p a(r a)$ que tengamos una fiesta, un ngillatun - dijo el chuncho. 
Y los pajaritos, los demás, le dijeron:

- ¡Güeno pu(es), eso está güeno! - -dijeron-. Vamos a hacer un ngillatun $p a(r a)$ el San Juan (JRPC/B1/b).

5.4. Los personajes, en cuanto interlocutores, utilizan también ciertas formas de apelación o vocativos para establecer una relación comunicativa más estrecha. En este sentido, las formas más utilizadas son similares a las que se usan en las conversaciones de la vida cotidiana: oye, hombre, compañero, compadre (a un amigo), hijo, hijito (a un joven); abuelita (a una anciana); mira, ve; usted, mire, patrón, (se)ñor. Los únicos vocativos que parecen extraños, y que son propios de textos de contenido ficticio, son las fórmulas de tratamiento de un súbdito a una dignidad real: señor Rey y $m i$ rey. La primera fórmula es análoga a señor Presidente, señor Ministro o señor Senador; y la segunda, que tiene el adjetivo posesivo mi, como elemento que precede al vocativo, parece una proyección de lo que es norma en los tratamientos de la jerarquía militar y policial: mi teniente, mi capitán, etc.

Ejs.:

(45) Y llama al doctor de cabecera que tenía. Le dijo:

- ¿Qué puedo hacer? ¿Qué me puede salvar?

- Mire, señor Rey -le dijo-, a usted lo único que lo puede salvar es que se ponga la camisa del hombre feliz (SBE/B2/m).

(46) - Miguelillo -le dijo-, tengo que conversar contigo. ¿Verdad que tú dijiste que te animabas a ir a buscar el lorito real que me ganó la vieja bruja?

- Nunca lo he dicho, mi Rey-le dijo (DC/B2/m).

5.5. Con respecto a otros marcadores textuales o discursivos, actualmente se sabe que la lengua dispone de una amplia y variada gama de ellos (vid. Martín Zorraquino y Montolío Durán 1988; Casado Velarde 1995); pero en los textos orales analizados, que provienen de personas no letradas, no se pueden esperar muchos recursos lingüísticos; sin embargo, los pocos marcadores utilizados aparecen y reaparecen constantemente y tanto por su forma y su función como por su reiteración deben ser considerados a la hora de abordar los hechos de la variación lingüística. Para la función de "comienzo discursivo" hay siempre bastante libertad en los textos orales de contenido realista; en cambio, en los textos de contenido ficticio, particularmente en la narración de cuentos, suelen encontrarse algunas 
fórmulas de apertura relativamente fijas: Había una vez, Éste era una vez, Habia un $x$, Éste era un $x$, Ésta era una $x, X$ era un $x$, Eran unos $x x, X$ andaba ..., X tenía ..., X estaba ..., etc. Tal vez esto no ofrezca mayor novedad, por eso omitiremos ejemplos. Más novedosos parecen los marcadores de "continuidad discursiva". En este sentido, llama la atención la función que suelen asumir el adverbio de tiempo entonces y la expresión de ahí, contraída muchas veces a di ahi. Entonces no solo funciona como adverbio que señala hacia un tiempo pasado inespecífico, sino que muchas veces pasa a indicar que la acción referida se enfrenta a una nueva situación y equivale, por lo tanto, a 'al momento', a 'luego' e incluso a 'por eso', donde pasa a tener una función inferencial. Con ello, es también marcador de continuidad discursiva. En cuanto a la expresión de ahí, que, por el adverbio de lugar que contiene, se podría esperar que cumpliera solamente una función localizadora, muchas veces asume un valor temporal equivalente a 'luego'; introduce una nueva información y, por eso, funciona como un marcador de continuidad discursiva. Similar función cumple la expresión en esto (o en eso), ya que equivale a 'al momento' e introduce también una nueva información.

Ejs.:

(47) Andaba él vendiendo y pilló una liebre. Entonces fue y la tomó y después fue y vendió un zapallo así tan grande. Entonces lo que pasó: el que lo compró [nunca había visto un zapallo] y era un aficionado a las carreras (RLF/B2/m).

(48) Ella no sabía qué lo que contenía soñar de pollo(s), de las ave(s). Entonces le preguntó ( ) su abuelita el sueño que tuvo, porque se soñó de aves (JRPC/B1/b).

(49) Pedro le dio una vuelta... ¡y saltó la chorrera de monedas!

$\mathrm{Y}$ de ahi es que le dijo:

- ¿Y cuánto... ? ¡Véndamela! (RFV/B2/m).

(50) Y le disparé yo. Pegó un grito harto fuerte y dejó los cachorritos ahí y arrancó. Y en esto llegó el perro, al disparo. El perro andaba detrás de la liebre (SRCS/B2/m).

5.6. Para la función de "reprobación" o "rechazo" de un hecho o de algo afirmado por el interlocutor, por lo general se emplea el adverbio de negación no o la negación reforzada no pu(es). Suelen usarse también formas exclamativas eufemísticas y disfemísticas, que en estos textos están usadas con mucha moderación, atendiendo a la situación comunicativa (entrevistado / entrevistador), que exige un estilo semiformal. Las que aparecen en 
estos textos son: iputa! y su equivalente eufemístico ipucha!; ;mierda!; ¡caramba!, eufemismo por 'carajo'; ;chuta!, eufemismo por ; chucha!, que alude vulgarmente a la 'vulva', y ichita!, que parece resto diminutivo de esa misma expresión (cfr. Rabanales 1953: 50-51). En los ejemplos citados en seguida, más que "reprobación" o "rechazo", expresan "sorpresa" y en algún caso incluso "complacencia" frente a una situación inesperada.

Ejs.:

(51) Y el gato como más listo:

- ¡Más adelante! -le gritó-. ¡Al mayor, compañero!

¡Puta!, los leones partieron. Casi se despedazan arrancando, oiga, antes que mataran otro $p u(e s)$. ¡Ja, ja, ja!

¡Chuta!, no volvieron más los leones. Y ellos, asusta(d)os también, pero se quedaron ahi $(\mathrm{JLM} / \mathrm{B} 3 / \mathrm{m})$.

(52) Entonces el joven fue al casamiento. ¡Pucha!, gran casamiento. Pero la niña no hablaba, estaba muda, no chillaba ni una cosa (JMP/B3/ $\mathrm{m})$.

(53) - ¿Y cómo lo sacó, compadre? -le dijo.

- iChita! Está la cosa tan fácil, compadre -le dijo-. Uste(d) echa la cola al agua -le dijo- y se sienta en (e)l agua, a la orillita del agua. El pesca(d)o va a venir de repente a pescarle la cola (SRCS/B2/m).

5.7. Para la función de "asentimiento" o "aprobación" de lo expuesto por uno de los participantes en una situación de diálogo, los textos orales presentan el uso de algunos marcadores clave: sí, bueno, claro y ya. A veces el narrador recurre a este último marcador para la función de "cierre" o "finalización" de un enunciado y también como recurso para reforzar su validez; otras veces lo emplea uno de los interlocutores para indicar aceptación de lo escuchado. Frecuente como marcador de "cierre" es también $p u$, forma reducida de pues (bastante distante de sus tradicionales funciones conjuntivas). La expresión no más sirve para esa misma función. A veces esta expresión se combina con $p u(e s)$ para reforzar la función conclusiva. Por su parte las combinaciones ya pu(es) y ya está, e incluso ya está pu(es), se emplean para aceptar una proposición y en otros casos para cerrar un enunciado o una secuencia.

Ejs.:

(54) El caballo había anda(d)o comiendo al la(d)ito de ahí donde él estaba acosta(d)o. Y no lo sintió pu(es).

Ya. Dijo: 
- Ahora vas a ir tú, Juan.

- $\underline{\text { Ya. }}$

Le pasó lo mismo (DC/B2/m).

- ¿De qué animal es este cuero? -le preguntaron.

Se recordó al tiro de hinojo y de las otras palabras:

- De piojo, pu(es).

Ya. Pero no le cayó bien al rey, ni a la reina, porque era pobre pu(es). Pero como era palabra de rey, tuvo que aceptar no más pu(es) $(\mathrm{BR} /$ $\mathrm{B} 2 / \mathrm{m})$.

(56) Le mandó el puñete. Alcanzó a meter el puro puño no más. Y¡ay! que se quejaba. Y era el primer puñete no más pu(es) $(\mathrm{JCH} / \mathrm{B} 3 / \mathrm{m})$.

(57) El zorro quiso cantar igual que un zorzal pu(es). Ya pu(es). Y le exigieron los hijos pa(ra) que cantara más fino. Ya. Se fue el zorro cantando, pero no podía cantar fino (JBPC/A4/b).

(58) ¡Qué!, no le importó. Era verano. Jue no más. ¡Y Ya está! (JAVQ/A6/m).

\section{CONCLUSIONES}

6.1. El castellano del área estudiada es bastante conservador a causa de los escasos vínculos de los hablantes con las formas de expresión utilizadas en los centros más poblados. Su léxico contiene algunos arcaísmos de raíz hispánica. Otro grupo de palabras proviene de la cultura huasa, formada con elementos hispano-criollos en la zona centro-sur del país. En ese conjunto léxico son notorios algunos términos de origen quechua relativos a la vida rural, todos ellos incorporados seguramente en tiempos de los primeros colonos españoles que traían del norte indígenas de servicio que proyectaron aquí elementos de su lengua primaria.

6.2. El castellano es abiertamente la lengua mayoritaria y dominante en el área de estudio, frente al mapudungun, lengua vernácula de contacto, que se mantiene actualmente solo en personas de mayor edad, para la comunicación entre iguales, sean parientes o amigos, y para los escasos ritos intraétnicos. Para propósitos de la vida pública, los mapuches han tenido que aprender el castellano, y esto ha estado reforzado por la educación sistemática. 
6.3. A pesar de la pérdida de vitalidad que presenta actualmente el mapudungun, ha dejado algunas huellas en la lengua dominante, principalmente en los nombres de ciertos objetos de la vida doméstica y de especies de la flora y de la fauna que abundan en la región. Naturalmente, el indigenismo en los mapuches bilingües tiene que ver sobre todo con ciertos elementos fundamentales de su cultura secular, que, como símbolos de identidad y resistencia, son actualizados de modo constante en diversas formas discursivas.

6.4. En el nivel morfosintáctico, el castellano hablado por wingkas y mapuches sigue algunas tendencias bastante generales. La más notoria es el uso de complemento indirecto y complemento directo reiterados, como recurso para hacer inequívoca la referencia. Otra tendencia es el voseo, aunque limitada a las formas verbales. El castellano hablado por mapuches bilingües suele presentar, además, algunos hechos exclusivos. Por ejemplo: algunas discordancias de género y número en las categorías nominales y discordancias de número y persona en la relación sujeto - verbo. También suele presentar vacilación o ausencia en el uso preposicional, especialmente de $a$ en complemento verbal y de de en complemento nominal, así como también en algunos casos ausencia u omisión de artículo. Estos hechos se deben efectivamente a diferencias estructurales que existen en la gramática de ambos sistemas lingüísticos (mapudungun y castellano) y que repercuten como proyección de estructuras de la lengua $\mathrm{A}$ en la lengua $\mathrm{B}$.

6.5. Una somera revisión de los recursos más comunes utilizados por los distintos hablantes entrevistados para dar cohesión a sus productos discursivos, más allá del nivel oracional, permite identificar algunos marcadores que establecen relaciones del texto con el nivel pragmático de los hablantes; otros que desempeñan funciones internas, como aquellos que sirven para establecer diferencias entre el discurso del narrador y el de los participantes de un diálogo; los que indican asentimiento, y otros, rechazo de afirmaciones o proposiciones; finalmente, los que propician la continuidad discursiva y los que indican el cierre de enunciados o de secuencias. Y lo más importante: los marcadores usados son poco variados, pero algunos de ellos -como le dijo, entonces, pu(es) у ya pu(es) - son muy recurrentes y, por ello, ayudan a caracterizar la variación lingüística aquí estudiada. 


\section{REFERENCIAS BIBLIOGRÁFICAS}

Aguirre Baztán, Ángel (ed.). 1997. Etnografia. Metodología cualitativa en la investigación sociocultural. México: Alfaomega / Marcombo.

Alonso, Amado. 1961. Examen de la teoría indigenista de Rodolfo Lenz. En Estudios lingüísticos. Temas hispanoamericanos. Madrid: Gredos, pp. 268-321.

Augusta, Fray Félix José DE. 1991 (1916). Diccionario Araucano. Mapuche-Español; Español -Mapuche. $2^{\mathrm{a}}$ edición. Temuco: Kushe.

Bernales Lillo, Mario. 2002. En busca de los nombres. Toponimia indígena e hispánica. Temuco: Ediciones Universidad de La Frontera.

Buesa Oliver, Tomás. 1965. Indoamericanismos léxicos en español. Madrid: Consejo Superior de Investigaciones Científicas (CSIC).

Casado Velarde, Manuel. 1995. Introducción a la gramática del texto del español, $2^{\mathrm{a}}$ ed. Madrid: Arco/Libros.

Cerda Hegerl, Patricia. 1996. Fronteras del Sur. La Región del Bio-Bio y la Araucanía chilena 1604-1883. Temuco: Ediciones Universidad de La Frontera.

Contreras, Constantino. 2005. Variación lingüística y cohesión discursiva (Observaciones sobre un corpus del castellano hablado en la Araucanía). LEA XXVII / 2: 195-217.

1999. El castellano hablado por mapuches. Rasgos del nivel morfosintáctico. Estudios Filológicos 34: 83-98.

DHACH. 1978. Diccionario del habla chilena. Academia Chilena de la Lengua. Santiago: Editorial Universitaria.

Elizaincín, Adolfo. 2007. Ocho precisiones sobre el contacto lingüístico. Lingüistica, Vol. 19: 117-132.

Fishman, Joshua. 1988. Sociología del lenguaje, trad. de R. Sarmiento y J. C. Moreno, $3^{\mathrm{a}}$ ed. Madrid: Cátedra.

Gómez Torrego, Leonardo. 2002. Análisis sintáctico. Teoría y práctica. Madrid: Ediciones SM.

Grau, Juan. 1998. Voces indígenas de uso común en Chile, $2^{\mathrm{a}}$ ed. Santiago de Chile: OIKOS.

Hernández Alonso, CÉSAR. 1995. Nueva sintaxis de la lengua española. Salamanca: Ediciones Colegio de España.

Hernández Sallés, Arturo, Nelly Ramos Pizarro y Rosa Huenchulaf Cayuqueo. 2006. Gramática Básica de la Lengua Mapuche, Tomo I. Temuco: Editorial Universidad Católica de Temuco.

Hoffmann, Alicia e Iván Lazo. 2000. Aves de Chile. Santiago de Chile: RIL Editores. 
Kany, Charles E. 1969. Sintaxis hispanoamericana. Madrid: Gredos.

LAPESA, RAFAel. 1981. Historia de la lengua española, $9^{\mathrm{a}}$ ed. Madrid: Gredos.

Martín Zorraquino, Ma A. y Estrella Montolío Durán (coords.). 1988. Los marcadores del discurso. Teoría y análisis. Madrid: Arco/Libros.

Moreno de Alba, José G. 1991. El español en América. México: FCE.

Moreno Fernández, Francisco (Recopilador). 1990. AlVAR, M. et al. Estudios sobre la variación lingüística. Alcalá de Henares: Universidad de Alcalá.

Morínigo, Marcos A. 1966. Diccionario manual de americanismos. Buenos Aires: Muchnick Editores.

Oroz, Rodolfo. 1966. La lengua castellana en Chile. Santiago de Chile: Universitaria.

Rabanales, Ambrosio. 1953. Introducción al estudio del español de Chile. Anejo $\mathrm{n}^{\circ} 1$ del Boletín de Filología. Universidad de Chile. Santiago: Universitaria.

Real Academia Española. 2001. Diccionario de la lengua española: Madrid: Espasa, vigésima segunda edición, 2 tomos.

SÁez, Leopoldo. 1999. El español de Chile en las postrimerías del siglo XX. Santiago de Chile: USACH.

SALAS, AdAlBerto. 1992: El mapuche o araucano. Madrid: MAPFRE.

1984. Textos Orales en Mapuche o Araucano del Centro-Sur de Chile. Concepción: Editorial de la Universidad de Concepción.

Zamora, Juan. 1988a. Dialectología. En Francesco D’Introno, Jorge Guitart y Juan Zamora. Fundamentos de Lingüística hispánica. Madrid: Playor; pp. 253-265.

1988b. Bilingüismo. En Francesco D’Introno, Jorge Guitart y Juan Zamora. Fundamentos de Lingüistica hispánica. Madrid: Playor, pp. 267-277.

Zamora Vicente, Alonso. 1979. Dialectología española, $2^{\mathrm{a}}$ ed. Madrid: Gredos.

Zimmermann, Klaus (ed.). 1995. Lenguas en contacto en Hispanoamérica. Madrid: Vervuert -Iberoamericana. 


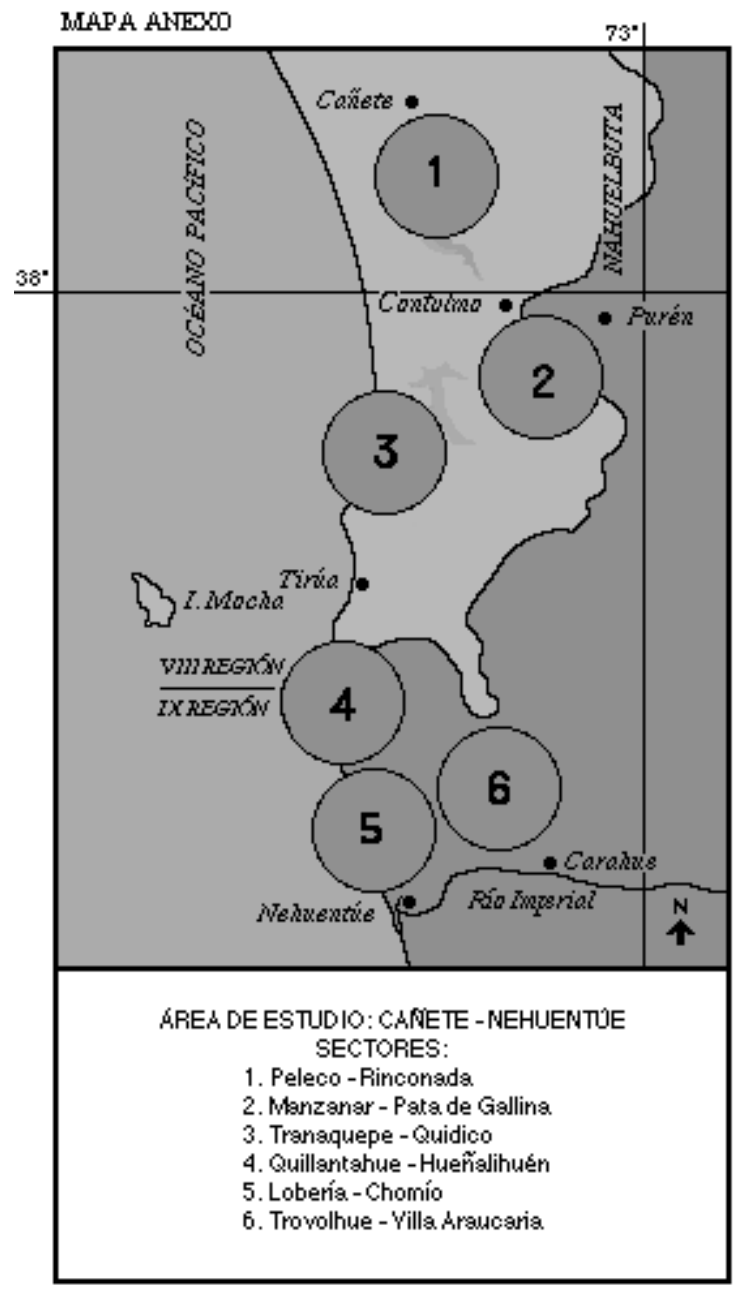

